Article

\title{
Cyclodextrin Complexed Lipid Nanoparticles of Irbesartan for Oral Applications: Design, Development, and In Vitro Characterization
}

\author{
Narendar Dudhipala ${ }^{1,2, *}$, Swetha Ettireddy ${ }^{2}$, Ahmed Adel Ali Youssef ${ }^{3}$ and Goverdhan Puchchakayala ${ }^{1,2}$ \\ 1 Department of Pharmaceutics, Vaagdevi Pharmacy College, Warangal 506005, Telangana, India; \\ goverdhanucpsc@gmail.com \\ 2 Synapse Life Sciences, Warangal 506001, Telangana, India; swethareddy532@gmail.com \\ 3 Department of Pharmaceutical Technology, Faculty of Pharmacy, Kafrelsheikh University, \\ Kafrelsheikh 33516, Egypt; eldiasti89@pharm.kfs.edu.eg \\ * Correspondence: narphmreddy@gmail.com
}

Citation: Dudhipala, N.; Ettireddy, S.; Youssef, A.A.A.; Puchchakayala, G. Cyclodextrin Complexed Lipid Nanoparticles of Irbesartan for Oral Applications: Design, Development, and In Vitro Characterization. Molecules 2021, 26, 7538. https:// doi.org $/ 10.3390 /$ molecules 26247538

Academic Editors: Jia-You Fang and Rita Cortesi

Received: 22 October 2021

Accepted: 10 December 2021

Published: 13 December 2021

Publisher's Note: MDPI stays neutral with regard to jurisdictional claims in published maps and institutional affiliations.

Copyright: (c) 2021 by the authors. Licensee MDPI, Basel, Switzerland. This article is an open access article distributed under the terms and conditions of the Creative Commons Attribution (CC BY) license (https:// creativecommons.org/licenses/by/ $4.0 /)$.

\begin{abstract}
Irbesartan (IR) is an angiotensin II receptor antagonist drug with antihypertensive activity. IR bioavailability is limited due to poor solubility and first-pass metabolism. The current investigation aimed to design, develop, and characterize the cyclodextrin(s) (CD) complexed IR (IR-CD) loaded solid lipid nanoparticles (IR-CD-SLNs) for enhanced solubility, sustained release behavior, and subsequently improved bioavailability through oral administration. Based on phase solubility studies, solid complexes were prepared by the coacervation followed by lyophilization method and characterized for drug content, inclusion efficiency, solubility, and in vitro dissolution. IR-CD inclusion complexes demonstrated enhancement of solubility and dissolution rate of IR. However, the dissolution efficiency was significantly increased with hydroxypropyl- $\beta C D$ (HP- $\beta C D)$ inclusion complex than beta-CD $(\beta C D)$. SLNs were obtained by hot homogenization coupled with the ultrasonication method with IR/HP- $\beta C D$ inclusion complex loaded into Dynasan 112 and glycerol monostearate (GMS). SLNs were evaluated for physicochemical characteristics, in vitro release, differential scanning calorimetry (DSC), powder X-ray diffractometry (PXRD), and physical stability at room temperature for two months. The optimized SLNs formulation showed particle size, polydispersity index, zeta potential, assay, and entrapment efficiency of $257.6 \pm 5.1 \mathrm{~nm}, 0.21 \pm 0.03,-30.5$ $\pm 4.1 \mathrm{mV}, 99.8 \pm 2.5$, and $93.7 \pm 2.5 \%$, respectively. IR-CD-SLN and IR-SLN dispersions showed sustained release of IR compared to the IR-CD inclusion complexes. DSC results complimented PXRD results by the absence of IR endothermic peak. Optimized IR-CD complex, IR-SLN, and IR-CD-SLN formulations were stable for two months at room temperature. Thus, the current IR oral formulation may exhibit improved oral bioavailability and prolonged antihypertensive activity, which may improve therapeutic outcomes in the treatment of hypertension and heart failure.
\end{abstract}

Keywords: irbesartan; complexation; cyclodextrin; solid lipid nanoparticles; sustained release

\section{Introduction}

Oral formulations account for around $90 \%$ of the global market share of all pharmaceutical formulations intended for human use. According to current estimates, orally administered pharmaceutical products account for about 84 percent of the best-selling pharmaceutical items, which are currently valued at $\$ 35$ billion and growing at a $10 \%$ yearly pace [1,2]. Patient compliance to oral medications is generally higher than other routes of administration such as intravenous, subcutaneous, and intramuscular, as well as to inhalation medications. Despite, this main advantage, the development of oral formulations poses several challenges. Oral bioavailability (BA) of poorly water-soluble drugs and drugs prone for first-pass metabolism often is low as their absorption could be kinetically limited by low rates of dissolution and/or capacity-limited by poor solubility when these drugs 
were administered in traditional solid formulations. Problems such as poor solubility or chemical stability in the environment of the gastrointestinal tract (GIT), poor permeability through the biological membranes, or sensitivity to metabolism are well known to result in the rejection of potential drug candidates as practical products $[3,4]$.

Various methodologies have been applied to enhance the oral BA of drugs with poor aqueous solubility [5-7]. Among various approaches, solid dispersions (SDs) are generally prepared using a hydrophilic polymer, and a drug with poor aqueous solubility by solvent evaporation, melting-extrusion, coprecipitation, or spray drying method to enhance the solubility and dissolution rate of poorly water-soluble drugs [8]. Formation of inclusion complex with drug molecules is another approach to increase the aqueous solubility of poorly water-soluble drugs, and it provides better control on the release rates of lipophilic drugs as well [9].

Lipid-based drug delivery systems are one of the emerging approaches, designed to address oral drug delivery challenges. Higher solubilization and absorption can be achieved by encapsulating or solubilizing drug molecules in lipid excipients, resulting in increased BA of the drug candidates. The use of lipid-based drug delivery systems such as SLNs have generated much academic and commercial interest as a potential formulation strategy for improving the oral BA and overcoming the hepatic first-pass metabolism. SLNs are used as an alternative carrier system to emulsions, liposomes, and polymeric micro and nanoparticles. SLNs are sub-micron spherical colloidal nanoparticles having a size range of 50-1000 nm with a drug-containing solid lipid core stabilized with surfactants [10]. SLNs enhance the BA of drug molecules by the uptake of the nanocarrier through the GIT directly, enhanced the permeability through the GI membrane, adhesion to the GI tract wall, and enhance intestinal lymphatic transport of the lipophilic drugs and therefore increase oral BA $[3,10]$. In addition, SLNs possess additional advantages; encapsulating both hydrophilic and lipophilic drugs, biocompatibility which is due to the biodegradable nature of lipids, controlled drug release rate, high drug content compared to other carrier systems, feasibility in scale-up, and suitability for other routes of administration such as oral, intravenous, pulmonary, ocular and transdermal drug administration [10-12].

Irbesartan (IR) is chemically 2-butyl-3-([2-\{1 H-tetrazole-5-yl\}biphenyl-4-yl]-1,3-diazaspiro $(4,4)$ non-1-en-4-one, a non-peptide angiotensin II type $1\left(\mathrm{AT}_{1}\right)$ receptor antagonist, used in the treatment of hypertension and heart failure $[13,14]$. The major drawback during therapeutic application of IR as an oral dosage form is its very low aqueous solubility $(91.3 \mu \mathrm{g} / \mathrm{mL})$ and first-pass metabolism [14,15]. According to Biopharmaceutical Classification System (BCS), IR is classified as a BCS class II drug (low aqueous solubility and high permeability).

Cyclodextrins (CDs) are widely used as excipients in pharmaceutical formulations. Inclusion complex formation using CDs with drug molecules came into existence as potential carriers to improve the oral delivery of lipophilic drugs [16]. CDs are cyclic oligosaccharides that are composed of glucopyranose units. The conical cylinder formed by the glucopyranose units has a hydrophobic interior cavity and a hydrophilic outer surface. Alpha, beta, and gamma $C D(\alpha C D, \beta C D$, and $\gamma C D)$ and their modified derivatives such as hydroxypropyl- $\beta C D(\mathrm{HP}-\beta C D)$, randomly methylated- $\beta C D$, and sulfobutylether- $\beta C D$ are the main family members that are chosen for inclusion complexation [1].

Previously, the solubility of IR was enhanced by complexation with $\beta C D$ and HP$\beta C D[17,18]$. IR: $\beta C D$ inclusion complex (IR- $\beta C D$ ) was prepared with three different methods such as co-grinding, kneading, and co-evaporation methods. Among these methods, the co-evaporation method was considered as a suitable method, in which the significant improvement in solubility and dissolution rate of the IR was observed compared with other methods and pure IR. In another study, IR-loaded SLNs (IR-SLNs) were reported to improve the oral BA of IR by 1.4-folds compared with IR alone in Wistar rats [19]. However, IR-CD complexed nanoformulations have not been reported till now. Therefore, we attempted to develop IR-CD-loaded SLNs (IR-CD-SLNs) to enhance solubility, promote lymphatic transport to minimize first-pass metabolism, and sustain IR release through oral 
administration. The objective of the current investigation was to prepare and characterize the optimized IR-CD complex with the co-evaporation followed by lyophilization method. In addition, IR-CD-SLNs and IR-SLNs formulations were prepared and optimized based on physicochemical characteristics and in vitro release studies. Furthermore, stability, and crystalline nature of IR-CD, IR-SLN and IR-CD-SLN formulations were evaluated.

\section{Materials and Methods}

IR was a kind gifted sample from Lupin Research Park Ltd., Pune, India. $\beta C D$ s (Molecular weight (MW), 1135) and HP- $\beta C D$ (MW. 1500) were a generous gift from Dr. Reddy's Labs Pvt Ltd. (Hyderabad, Telangana, India). Tween ${ }^{\circledR}$ 80, Dynasan 112, and Poloxamer 188 were purchased from Sigma-Aldrich Chemicals (Bangalore, Karnataka, India). Glycerol monostearate (GMS) was purchased from RX CHEMICALS (Navi Mumbai, Maharashtra 400705, India). Soylecithin was a generous gift from Lipoid (Ludwigshafen am Rhein, Germany). Methanol, acetonitrile, chloroform, and ethanol were of HPLC grade (Merck, Bengaluru, Karnataka, India). Centrisart filters (M.W. cut off 20,000 kD) were purchased from Sartorius (August-Spindler-Straße 11, 37079 Göttingen, Germany).

\subsection{Quantification of IR by HPLC}

IR was quantified using a slightly modified reported HPLC method [20]. The HPLC system consists of LC-20 AD solvent delivery unit with reverse-phase Merck C18 $(250 \times 4.6 \mathrm{~mm}$; 5 microns) (Lichrosphere, Merck, Germany) column, was equilibrated with an eluent mixture of phosphate buffer $(\mathrm{pH} 4) /$ acetonitrile $(50: 50, v / v)$ pumped isocratically at a flow rate of $1 \mathrm{~mL} / \mathrm{min}$. The peaks were obtained at $270 \mathrm{~nm}$ wavelength using an SPD-20AV ultraviolet detector (Shimadzu, Japan). All the samples were analyzed at $25^{\circ} \mathrm{C}$ at absorbance units full scale (AUFS) 1.00 and $20 \mu \mathrm{L}$ injection volume. Before the elution, the mobile phase was filtered (Millipore system, $0.2 \mu \mathrm{m}$ ) under vacuum and degassed. The total run time for the analysis was $5 \mathrm{~min}$.

\subsection{Phase Solubility Studies:}

Phase solubility studies with increasing concentration of $\beta C D$ and $\mathrm{HP}-\beta C D(0.1,0.25$, $1,1.5,2.5,4$, and 5 millimole ratio) were performed according to the method described by Higuchi and Connors [21]. Briefly, an excess amount of the drug was added to $10 \mathrm{~mL}$ of double-distilled water containing various concentrations of $\beta C D$ and HP- $\beta C D$ in a stoppered glass vial. The suspensions were vigorously shaken at $25 \pm 1{ }^{\circ} \mathrm{C}$ for $72 \mathrm{~h}$ on a rotary shaker. After equilibrium was attained, the samples were filtered through a $0.45 \mu \mathrm{m}$ Millipore membrane filter and suitably diluted. These samples were assayed for the drug content by UV spectrophotometer against blank in the same concentration of $\beta C D$ or $\mathrm{HP}-\beta C D$ in water. The solubility experiments were conducted in triplicate. The IR-CD apparent stability constant $\mathrm{K}_{1: 1}$ and the complex efficiency (CE) were calculated from the slope of the linear plot of the phase solubility diagram and the solubility of IR alone in water without the complexing agents according to Equations (1) and (2).

$$
\mathrm{K}_{1: 1}=\frac{\text { Slope }}{\mathrm{S}_{0}(1-\text { Slope })}
$$

where $S_{0}$ is drug solubility in the absence of $\beta C D$ and HP- $\beta C D$ (intercept).

$$
\mathrm{CE}=\mathrm{S}_{0} \times \mathrm{K}_{1: 1}=\frac{\text { Slope }}{1-\text { Slope }}
$$

\subsection{Preparation of Physical Mixture}

Physical mixtures (PM) of IR- $\beta C D$ and IR-HP- $\beta C D$ in the ratio of $1: 1$ were prepared by mixing of individual components (weighed amount of IR, $\beta C D$, and HP- $\beta C D$ ) that had been previously sieved through a mesh no. 80 sieve $(180 \mu \mathrm{m})$ in a glass mortar until a homogeneous mixture was obtained [22]. Then, these mixtures were stored in the 
desiccators. This mixture was used for the comparative study with IR- $\beta C D$ and IR-HP- $\beta C D$ lyophilized products.

\subsection{Preparation of $S D s$}

Based on phase solubility graphs an AL-type means that the complexation ratio of CD: IR is on a 1:1 molar basis. Briefly, the CD was dissolved in distilled water to prepare CD solution $(1 \mathrm{mM})$, and a 30\% methanolic solution containing IR was prepared. The methanolic solution of IR was dropped stepwise to the aqueous solution of CDs. The mixture was stirred at $600 \mathrm{rpm}$ for $6 \mathrm{~h}$ until a stable suspension was formed on a magnetic stirrer to obtain complexation equilibrium. The suspension was further sonicated. Then, the clear solution was kept on a magnetic stirrer until all solvent molecules were evaporated. All the clear solutions were frozen at $-20{ }^{\circ} \mathrm{C}$ and the frozen mass was lyophilized in a freeze-dryer (Lyodel, Delvac Pumps Pvt. Ltd., Kanchipuram, Tamil Nadu, India) for $72 \mathrm{~h}$ to obtain a dry powder of IR- $\beta C D$ and IR-HP- $\beta C D$ SD formulations.

\subsection{Drug Content}

The drug content of SDs and PM was assayed to calculate the equivalent amount of IR to be used. The drug content in the prepared SD and PM formulations was analyzed by taking an appropriate weighed quantity (in triplicate), dissolving in $25 \mathrm{~mL}$ of methanol in a conical flask, and keeping in a rotary shaker for $1 \mathrm{~h}$. Then, samples were centrifuged at 15,000 rpm for $15 \mathrm{~min}$ and the collected supernatant was filtered through a $0.45 \mu \mathrm{m}$ membrane filter, properly diluted, and analyzed spectrophotometrically at a UV detection $\lambda$ of $220 \mathrm{~nm}$ (SL-159, Elico Ltd., Hydrabad, Telangana 500018, India).

\subsection{Inclusion Efficiency}

The prepared SDs and PMs were dissolved in $10 \mathrm{~mL}$ methanol in $10 \mathrm{~mL}$ volumetric flasks, mixed thoroughly, and sonicated for $30 \mathrm{~min}$. After proper dilution with methanol, the solution was analyzed spectrophotometrically at a UV detection $\lambda$ of $220 \mathrm{~nm}$.

\subsection{In Vitro Dissolution Study}

SDs, PMs, and pure IR were subjected to in vitro dissolution test to ascertain the role of CDs in enhancing the dissolution behavior of hydrophobic drugs. The test was performed in triplicate using USP type II apparatus (Paddle) (TDT-06P, Eletrolab, Goregaon East, Mumbai, Maharashtra 400063, India) in phosphate buffer (pH 6.8, $\left.37 \pm 0.5^{\circ} \mathrm{C}, 50 \mathrm{rpm}\right)$ as the dissolution medium. Relevant quantities of formulations (SDs and PMs) and IR equivalent to $5 \mathrm{mg}$ dose were placed into the dissolution media. Aliquots of $5 \mathrm{~mL}$ were withdrawn at predetermined time intervals and replaced with an equal volume of fresh medium. Samples were analyzed using a UV spectrophotometer.

\subsection{Dissolution Studies}

The percentage cumulative amount of IR released in 15 and $60 \mathrm{~min}$ (Q 15 and Q 60 respectively) were derived from the in vitro dissolution release profile. Data were processed using the statistical function of Microsoft $365^{\circledR}$ office excel (2019, Microsoft Corporation, Redmond, WA, USA).

\subsection{Dissolution Efficiency (DE)}

$D E$ is defined as the area under the dissolution curve up to a certain time $(t)$, expressed as a percentage of the area of the rectangle described by $100 \%$ dissolution at the same time. DE was calculated by using Equation (3):

$$
\% \mathrm{DE}=\frac{\int_{0}^{\mathrm{t}} \mathrm{y} \times \mathrm{dt}}{\mathrm{y}_{100} \times \mathrm{t}} \times 100
$$


where $\mathrm{y}$ is the percentage of dissolved product, $\mathrm{t}$ is time, and $\mathrm{y}_{100}$ is expressed as a percentage of the curve at maximum dissolution.

\subsubsection{Mean Dissolution Rate (MDR)}

The sum of the drug coming into the bulk of dissolution media per unit time under in vitro dissolution conditions is defined as the MDR. MDR was calculated by using Equation (4):

$$
\operatorname{MDR}=\frac{\sum_{j=1}^{n} \Delta M_{j} / \Delta t}{n}
$$

where $\Delta M_{j}$ is the additional amount of drug dissolved between $t_{j}$ and $t_{1}, n$ is the number of in vitro dissolution sample times, $\Delta t$ is the midpoint time between $t_{j}$ and $t_{1}$ which can be easily calculated with $\left(t+t_{1}\right) / 2$.

\subsubsection{Mean Dissolution Time (MDT)}

MDT was calculated to assess the comparative extent of the dissolution rate enhancement from CDs. It is defined as the time taken for dissolving a molecule from a solid dosage. MDT was calculated according to Equation (5):

$$
\mathrm{MDT}_{\text {in vitro }}=\frac{\sum_{\mathrm{i}=1}^{\mathrm{n}} \mathrm{t}_{\text {mid }} \cdot \Delta \mathrm{M}}{\sum_{\mathrm{i}=1}^{\mathrm{n}} \Delta \mathrm{M}}
$$

where $\mathrm{i}$ is the in vitro dissolution sample number, $\mathrm{n}$ defines the number of sample time points, $t_{\text {mid }}$ is the midpoint of the ith period easily calculated with $\left[t+t_{1}\right) / 2$ and $\Delta M$ is the additional amount of drug dissolved between $t_{i}$ and $t_{1}$.

\subsubsection{Initial Dissolution Rate (IDR)}

IDR is the first $15 \mathrm{~min}$ dissolution rate during the in vitro dissolution study and is called the dissolution rate.

\subsection{Preparation of IR-SLNs and IR-CD-SLNS}

SLNs were prepared by the hot homogenization coupled with the ultrasonication method [23]. Briefly, IR, solid lipid (GMS or Dynasan 112), and soylecithin were dissolved in $5 \mathrm{~mL}$ of 1:1 chloroform and methanol mixture for SLNs preparation. Organic solvents were removed completely using a rotary evaporator (Heidolph, Schwabach, Germany). The drug-containing oily phase layer was melted by heating above the melting point of the solid lipid by $5{ }^{\circ} \mathrm{C}$. However, during the preparation of IR-CD-SLNs, IR was added as an inclusion complex to the aqueous phase. An aqueous phase consisting of IR-CD complex $(52.6 \mathrm{mg})$ and/or Poloxamer $188(1.5 \% \mathrm{w} / \mathrm{v})$ was dissolved in double-distilled water to prepare the aqueous phase and heated to the same temperature as the oily phase. The hot aqueous phase was added dropwise to the oily phase under continuous magnetic stirring at $2000 \mathrm{rpm}$ for $5 \mathrm{~min}$ and homogenized at 16,000 rpm using a high-speed homogenizer (Diax900, Heidolph, Germany) for another $5 \mathrm{~min}$. The obtained O/W emulsion was ultrasonicated using a $12 \mathrm{~T}$ probe Sonicator (Vibracell, Sonics, CT, USA) for 25 min at $40 \%$ amplitude with a 10-sec pulse ON and 10-sec pulse OFF. SLNs were obtained by allowing hot nanoemulsion to cool at room temperature. The drug load of IR in SLNs was maintained at $0.1 \% \mathrm{w} / \mathrm{v}(1 \mathrm{mg} / \mathrm{mL})$.

\subsection{Preparation of IR Suspension (IR-CS)}

IR-CS was prepared by dissolving $0.1 \% w / v$ of IR in double-distilled water by using $1 \% w / v$ Tween ${ }^{\circledR} 80$ as a suspending agent. The mixture was stirred for $1 \mathrm{~h}$ at $2000 \mathrm{rpm}$ at $40{ }^{\circ} \mathrm{C}$, followed by $1 \mathrm{~h}$ at room temperature. 


\subsection{Characterization of IR-SLNS and IR-CD-SLNS}

2.12.1. Particle Size (PS), Polydispersity Index (PDI), and Zeta Potential (ZP)

The PS, PDI, and ZP of SLNs were measured using a Malvern Zetasizer (Nano ZS90, Malvern Panalytical Ltd, Enigma Business Park, Grovewood Rd, Malvern WR14 1XZ, UK). For the measurement of PS and PDI, the prepared SLNs of $100 \mu \mathrm{L}$ were diluted to $5 \mathrm{~mL}$ with double distilled water to get optimum Kilo Counts Per Second (KCPS) of above 100 for measurements. ZP of the SLN formulations was measured using the electrode cell based on the Smoluchowski equation using the same diluted sample. All analyses were carried out in triplicate at $25^{\circ} \mathrm{C}$ [24].

\subsubsection{Drug Content}

About $100 \mu \mathrm{L}$ of the IR-loaded SLNs was dissolved in a $900 \mu \mathrm{L}$ mixture of chloroform and methanol (1:1), vortexed for $5 \mathrm{~min}$, and centrifuged at 15,000 rpm for $15 \mathrm{~min}$ (Remi Laboratory Instruments, Cama Industrial Estate, Goregaon, Mumbai, Maharashtra 400063, India). The samples were further diluted with the mobile phase before injection into the HPLC column [25]. The amount of IR in SLN formulations was quantified using the HPLC method mentioned above. The IR content (assay) was used to calculate the percentage entrapment efficiency of IR in SLNs.

\subsubsection{Entrapment Efficiency (EE)}

EE was determined by measuring the concentration of the free drug (unentrapped) in the external aqueous phase based on an earlier reported method [26]. The aqueous medium was separated by ultra-filtration using centrisart tubes (Sartorius, Goettingen, Germany), which consisted of a filter membrane (Mwt. cut off $20 \mathrm{KDa}$ ) at the base of the sample recovery chamber. About $2.5 \mathrm{~mL}$ of the SLNs were placed in the outer chamber, and the sample recovery chamber was placed on top of the sample and centrifuged at 15,000 rpm for $15 \mathrm{~min}$. The SLNs, along with the encapsulated drug, remained in the outer chamber and the aqueous phase moved into the sample recovery chamber through the filter membrane. The amount of IR in the aqueous phase was estimated using the above described HPLC method. The EE of the IR-LNFs were calculated using the following equation:

$$
\% \mathrm{EE}=\left[\frac{\text { Amount of IR in assay }- \text { Amount of the unentrapped IR }}{\text { Amount of weighed IR }}\right] \times 100
$$

\subsubsection{In Vitro Release Studies}

The dialysis method was performed for in vitro release testing using Franz diffusion cells. Dialysis membrane (Hi-Media, Mumbai, India) having pore size $2.4 \mathrm{~nm}$ and MW cutoff between 12,000-14,000 kD was used for the release studies [27]. The dialysis membrane was soaked overnight in double distilled water before the release studies. Phosphate buffer ( $\mathrm{pH}$ 7.4) with $40 \%$ ethanol was used as the release medium [27]. According to USP, organic cosolvents such as ethanol are routinely added as solubility modifiers to the aqueous dissolution media to afford sink conditions. The experimental unit was consisting of a donor and receiver compartment. The donor compartment contained $0.5 \mathrm{~mL}$ of the SLN formulation, and the receiver compartment had $12 \mathrm{~mL}$ of a freshly prepared release medium. The diffusion cell temperature was maintained at $37 \pm 0.5^{\circ} \mathrm{C}$. At $0.5,1,2,3$, $4,6,8,10,12,24$, and $48 \mathrm{~h}$ time points, a $1 \mathrm{~mL}$ sample was withdrawn from the receiver compartment and replaced with an equal volume of the fresh receiver medium. The collected samples were analyzed for IR using HPLC to obtain the \% cumulative amount released vs time profile.

\subsubsection{Lyophilization}

The optimized IR-SLN and IR-CD-SLN formulation containing trehalose dihydrate as a cryoprotectant $(10 \% w / w)$ were lyophilized in a freeze dryer (Lyodel, Delvac Pumps Pvt. Ltd., Tamil Nadu, India) to form a dry and free-flowing powder. The vacuum was 
applied, and the frozen samples were subjected to various drying phases for about $24 \mathrm{~h}$ to get the lyophilized SLNs product [28]. Lyophilized SLNs were reconstituted and used for further studies. The frozen samples were obtained by keeping the samples overnight in an ultra-freezer at $-80^{\circ} \mathrm{C}$ (Sanyo Electric Co., Ltd., Moriguchi, Osaka prefecture, Japan).

\subsection{Solid-State Characterization}

\subsubsection{Differential Scanning Calorimetry (DSC)}

DSC is a thermodynamical tool for the assessment of the heat energy uptake under a regulated increase or decrease in temperature that occurs within a sample. DSC is one of the most common techniques for determining drug-excipient compatibility and the crystalline behavior of the drug and other different excipients. DSC thermograms of pure IR, pure CD, pure solid lipid, PM of IR, and solid lipid (1:1), freeze-dried IR-CD inclusion complex (1:1), lyophilized IR-SLNs, and lyophilized IR-CD-SLNs were obtained by DSC 822 e/ 200 (Mettler-Toledo (Schweiz) GmbH, Im Langacher 44, 8606 Greifensee Schweiz, Switzerland) instrument. Enthalpy changes during endothermic or exothermic changes were quantified. The instrument was calibrated with indium (calibration standard, purity $>99.99 \%$ ) before the analysis. About $8 \mathrm{mg}$ sample was used for analysis into a standard aluminum pan while an empty pan was used as a reference. The heating rate was increased at the rate of $10{ }^{\circ} \mathrm{C} / \mathrm{min}$ and the obtained thermograms were observed for crystallinity changes and compatibility of IR with other excipients.

\subsubsection{Powder X-ray Diffraction (PXRD)}

$X R D$ technique was used to assess the polymorphic transitions (if any) of IR loaded into CD inclusion complex and SLNs formulations. XRD patterns of samples were recorded on a powder X-ray diffractometer (XRD 6000, SHIMADZU CORPORATION, 3, Kandanishiki-cho 1-chome Chiyoda-ku, Tokyo 101-8448, Japan), operating in the $\theta-2 \theta$ mode. The radiation originated from the source $(40 \mathrm{kV}$ and $30 \mathrm{~mA})$ goes through a nickel filtered $\mathrm{CuK} \alpha$. Diffraction data were collected over a range of angles from $2{ }^{\circ} \mathrm{C}$ to $50^{\circ}$, at a step size of $0.045^{\circ}$ and step time of $0.5 \mathrm{~s}$, with an overall scan time of approximately $50 \mathrm{~min}$. The samples were mounted on a glass sample holder. Diffraction patterns were simulated from published single-crystal X-ray diffraction data. Samples used for XRD analysis were pure IR, pure solid lipid, physical mixture of solid lipid and IR, and lyophilized IR-CD inclusion complex and IR-CD-SLNs formulations.

\subsubsection{Stability Studies of IR-CD, IR-SLN, and IR-CD-SLN}

Optimized IR-CD inclusion complex, IR-SLN, and IR-CD-SLN formulations were subjected to stability studies by the storage of the formulations at room temperature (RT). Formulations were packed in 20-mL-capacity scintillation glass vails and kept at $25 \pm 2{ }^{\circ} \mathrm{C}$ for 60 days. Samples were withdrawn at predetermined time intervals and analyzed [29]. Changes in parameters such as drug content and inclusion efficiency and PS, PDI, ZP, assay, and EE of IR-CD complex and IR-SLN, IR-CD-SLN, respectively were recorded.

\subsubsection{Statistical Analysis}

The statistical significance comparison of data was made with an unpaired Student's ttest using GraphPad prism software (version 5.02, 2013, San Diego, CA, USA). A statistically significant difference was observed at a ' $p$ ' value less than $0.05(p<0.05)$.

\section{Results and Discussion}

\subsection{Phase Solubility Studies}

The ability of a CD to form an inclusion complex is a function of steric as well as thermodynamic factors [30]. The driving force leading to inclusion complexation involves the exclusion of hydrophobic cavity-bound high-energy water and formation of Van der Waals forces, hydrophobic, electrostatic, and hydrogen bond interactions as well as chargetransfer interaction [30]. CDs can form inclusion complexes with low aqueous solubility 
drugs and change the physicochemical and biological properties of guest molecules due to their unique structure [31,32]. CDs act as permeation enhancers by carrying the drug through the aqueous barrier, from the bulk solution inside the GI tract to the lipophilic surface of biological membranes, where the drug molecules can partition easily from the inclusion complex into the lipophilic membrane [30]. Moreover, CDs have the added other advantage of improving the chemical stability of drug molecules, especially esters, by protecting chemically labile substances from potentially tough environmental conditions and reducing also the enzymatic degradation, oxidation, or hydrolysis [1].

The phase solubility profiles of IR- $\beta C D$ and IR-HP- $\beta C D$ are presented in Figure 1. The solubility of IR was increased with the increasing concentration of $\beta C D$ and $H P-\beta C D$; therefore, this phase solubility diagram could be classified as $A_{L}$ type according to Higuchi and Connors [22,33]. A complex with a 1:1 molar ratio was formed, according to the linear host-guest correlation (correlation coefficient $R^{2} 0.97$ and 0.96 for $\beta C D$ and HP- $\beta C D$ respectively). Furthermore, $\mathrm{K}_{1: 1}$ was $642.7 \mathrm{M}^{-1}$ and $491.6 \mathrm{M}^{-1}$ for IR- $\beta C D$ and IR-HP- $\beta C D$, respectively. The reported value of $K_{1: 1}$ is most often between 50 and $2000 \mathrm{M}^{-1}$ with a reported mean value of $490 \mathrm{M}^{-1}$ for the parent $\beta C D$ [34,35]. However, the determined $\mathrm{K}_{1: 1}$ value is strongly affected by the intercept. The feasibility of using CDs as pharmaceutical excipients can be calculated from $\mathrm{K}_{1: 1}$ and $\mathrm{S}_{0}$ [34]. The results came in accordance with Hirlekar et al. and Leoins et al. $[17,22]$.

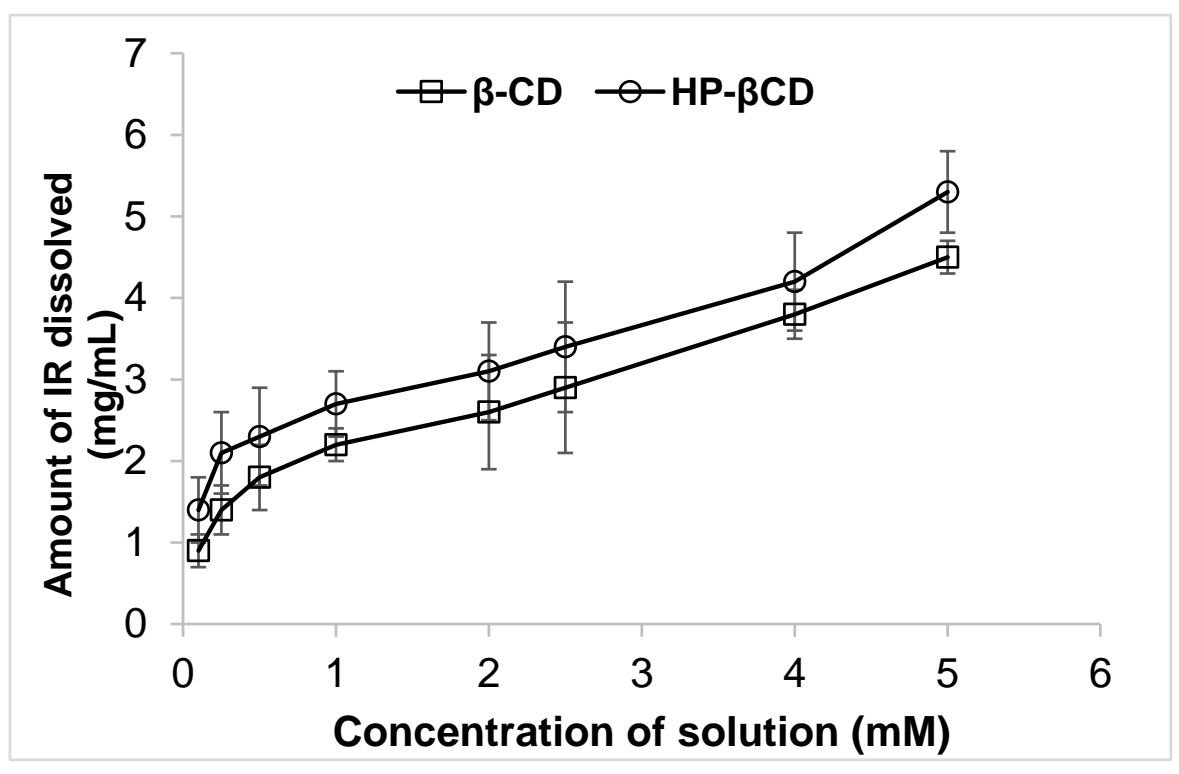

Figure 1. Phase solubility diagram of IR- $\beta C D$ and IR-HP- $\beta C D$ inclusion complex in water at $25 \pm 2{ }^{\circ} \mathrm{C}($ mean $\pm \mathrm{SD}, n=4)$.

\subsection{Drug Content and Inclusion Efficiency}

The CE of the CDs in the aqueous vehicle is the key aspect and not the absolute value of $\mathrm{K}_{1: 1} \cdot \mathrm{S}_{0}$ is sharply affected by many pharmaceutical excipients such as preservatives, buffer salts, and polymers, and sometimes $\mathrm{S}_{0}$ is below the detection limit of the analytical method used for the quantitative determination of the drug. Since the numerical value of $\mathrm{CE}$ is dependent only on the slope of the phase-solubility profile; therefore, less variation is usually observed in the value of $C E$ compared to the $\mathrm{K}_{1: 1}$ value. The obtained results are summarized in Table 1 . The $\%$ complexation efficiency was $93.9 \pm 2.2-75.2 \pm 2.3$ for IR- $\beta C D$ inclusion complex, compared to $95.6 \pm 3.1-80.6 \pm 2.2$ for IR-HP- $\beta C D$ inclusion complex. The relative standard deviation (RSD) values in the limits of $\pm 5 \%$ indicate that there are no significant changes by the sample processing. IR: $\beta C D(1: 4)$ and IR: HP$\beta C D$ (1:4) showed the best results regarding drug content, inclusion efficiency, and folds improvement in IR solubility. Therefore, these two formulations have been considered as the optimized formulations for further dissolution studies. 
Table 1. Drug content and inclusion efficiency of irbesartan from PMs, IR- $\beta C D$, and IR-HP- $\beta C D$ inclusion complexes (mean $\pm \mathrm{SD}, n=4)$.

\begin{tabular}{ccccc}
\hline & & & \multicolumn{2}{c}{$\begin{array}{c}\text { Solubility Parameters } \\
\text { at 25 }{ }^{\circ} \mathbf{C}\end{array}$} \\
\cline { 4 - 5 } Formulations & $\begin{array}{c}\text { Drug Content } \\
(\mathbf{\%})\end{array}$ & $\begin{array}{c}\text { Inclusion } \\
\text { Efficiency (\%) }\end{array}$ & $\begin{array}{c}\text { Solubility } \\
(\mathbf{m g} / \mathbf{m L})\end{array}$ & Folds Improved \\
\hline Water & - & - & $0.1 \pm 0.03$ & - \\
PM $\beta C D(1: 1)$ & $89.1 \pm 2.4$ & $68.3 \pm 2.1$ & $0.8 \pm 0.3$ & 8 \\
PM HP- $\beta C D(1: 1)$ & $92.9 \pm 1.7$ & $71.5 \pm 1.8$ & $1.2 \pm 0.1$ & 12 \\
IR $\beta C D(1: 1)$ & $93.6 \pm 1.2$ & $75.2 \pm 2.3$ & $1.8 \pm 0.5$ & 18 \\
IR $\beta C D(1: 2.5)$ & $92.3 \pm 2.5$ & $85.2 \pm 1.7$ & $2.3 \pm 0.3$ & 23 \\
IR $\beta C D(1: 4)$ & $96.6 \pm 3.1$ & $93.9 \pm 2.2$ & $3.4 \pm 0.4$ & 34 \\
IR HP- $\beta C D(1: 1)$ & $96.2 \pm 1.9$ & $80.6 \pm 2.2$ & $2.5 \pm 0.3$ & 25 \\
IR HP- $\beta C D(1: 2.5)$ & $95.3 \pm 2.1$ & $86.2 \pm 1.7$ & $3.2 \pm 0.6$ & 32 \\
IR HP- $\beta C D(1: 4)$ & $98.2 \pm 3.0$ & $95.6 \pm 3.1$ & $4.8 \pm 0.8$ & 48 \\
\hline
\end{tabular}

\subsection{Analysis of Dissolution Data}

The dissolution profiles of pure IR, PMs and the IR-CDs inclusion complexes are depicted in Figure 2. The release rate profiles were plotted as the percentage of IR released vs time. According to these results, the inclusion complexes released up to 76.2 and $94.4 \%$ of the drug in $60 \mathrm{~min}$ from IR- $\beta C D$ and IR-HP- $\beta C D$, respectively, whereas the pure drug exhibited the release of $\sim 7.6 \%$ after $15 \mathrm{~min}$ and not more than $15.3 \%$ at $60 \mathrm{~min}$. However, $\mathrm{PM}$ of IR/ $\beta C D$ and PM of IR/HP- $\beta C D$ released up to 40.7 and $43.9 \%$ of the drug in $60 \mathrm{~min}$, respectively. These quantities contrast with the markedly 4.9 - and 6.2-fold increase in the release of IR- $\beta C D$ and IR-HP- $\beta C D$, respectively compared to the pure drug. Additionally, the results showed a marked 1.9- and 2.2-fold increase in the release of IR- $\beta C D$ and IR-HP$\beta C D$, respectively, compared to the corresponding PMs. DE values at 15 and 60 min are shown in Table 2. DE are suitable parameters for the evaluation and comparison of the in vitro dissolution of different formulations. This parameter is defined as the area under the dissolution curve (AUC) up to a specific time, $t$, expressed as the rectangle described by $100 \%$ dissolution in the same time [36]. The DE (60 min) of the IR- $\beta$ CD formulation is 2.8- and 1.9-fold greater as compared to the drug alone and the corresponding physical mixture, respectively. However, the DE (60 $\mathrm{min}$ ) of the IR-HP- $\beta$ CD formulation is 3.4- and 1.4-fold greater as compared to the drug alone and the corresponding physical mixture, respectively. All the formulations containing CDs showed a significant difference in the DE with respect to IR $(p<0.05)$. The maximum dissolution of active pharmaceutical ingredients from a dosage form in a particular period of time is not the only standard related to drug absorption, despite the pharmacopoeial test methods would show otherwise. The dissolution rate is also critical and is frequently the rate-limiting process for drug absorption [37]. A calculation of the rate of dissolution would necessitate the development of a suitable kinetic law. However, the complex agent dissolution and drug dissolution, overlap, and such a technique would have to be approached with caution. MDT is used as a model-independent approach. The MDT reflects the dissolution rate and the shorter MDT, the faster the progress of the dissolution process. The values for MDT are shown in Table 2. PMs showed an insignificant difference in MDT when compared to the pure drug $(p>0.05)$; while, the corresponding inclusion complexes showed a significant difference in MDT $(p<0.05)$, compared to the pure IR. CDs are useful excipients that have widespread attention and use in pharmaceutics and drug delivery. The reason for this popularity is the ability of these excipients to interact with lipophilic drug candidates resulting in an increase in the apparent water solubility of these drug candidates. In this regard, this solubilization mechanism is due to the ability of CDs to form non-covalent dynamic inclusion complexes in the solution. Moreover, the solubilizing mechanisms may include the formation of a non-inclusion-based complex, the formation of aggregates and related domains, and the ability of CDs to form and stabilize supersaturated drug solutions [38-40]. The increase 
in IR solubility also can increase the dissolution rate and thus could improve the oral bioavailability of IR [39]. Based on the dissolution studies and its parameters, IR/HP- $\beta C D$ inclusion complex was selected to be loaded in SLNs formulations.

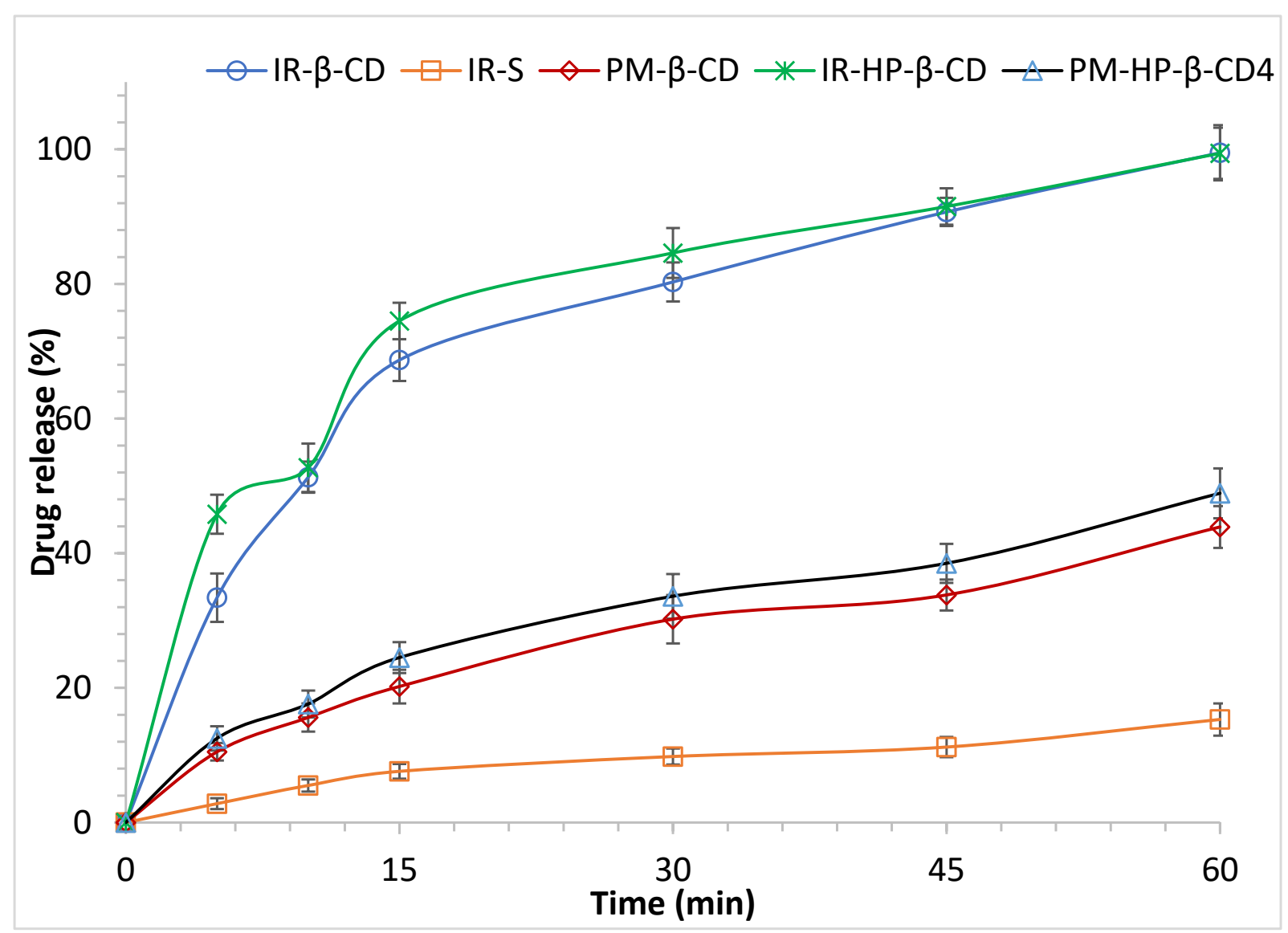

Figure 2. The in vitro release profile of irbesartan from irbesartan solution, PMs, and the corresponding cyclodextrin inclusion complexes in phosphate buffer (Mean $\pm \mathrm{SD}, n=4$ ).

Table 2. Dissolution parameters of irbesartan from irbesartan solution, PMs, IR- $\beta C D$, and IR-HP- $\beta C D$ inclusion complexes (mean $\pm \mathrm{SD}, n=4$ ).

\begin{tabular}{cccccccc}
\hline \multirow{2}{*}{ Formulation } & \multicolumn{7}{c}{ Dissolution Parameter } \\
\cline { 2 - 8 } & $\mathbf{Q}_{\mathbf{1 5}}$ & $\mathbf{Q}_{\mathbf{6 0}}$ & $\mathbf{D E}_{\mathbf{1 5}}$ & $\mathbf{D E}_{\mathbf{6 0}}$ & $\mathbf{M D T}$ & MDR & IDR \\
\hline IR $^{*}$ & 7.6 & 15.3 & 12.5 & 21.1 & 24.2 & 0.2 & 1.2 \\
\hline PM- $\beta C D$ & 27.7 & 40.7 & 21.9 & 31.2 & 23.0 & 0.5 & 1.8 \\
\hline IR- $\beta$ CD (1:4) & 68.7 & 76.2 & 28.4 & 59.4 & 15.5 & 1.3 & 4.4 \\
\hline PM HP- $\beta C D$ & 29.9 & 43.9 & 12.5 & 52.5 & 22.2 & 1.2 & 1.9 \\
\hline IR-HP- $\beta C D(1: 4)$ & 76.9 & 94.4 & 35.3 & 72.4 & 13.4 & 1.6 & 5.1 \\
\hline
\end{tabular}

*IR-Irbesartan; PM- $\beta C D$ and PM-HP- $\beta C D-$ a physical mixture of irbesartan with $\beta C D$ and HP- $\beta C D$, respectively

\subsection{IR-SLNS and IR-CD-SLNS}

Four different SLN formulations were prepared using Dynasan 112 and GSM, selected based on earlier reported studies [19]. The composition of all prepared SLN formulations is shown in Table 3. Surfactants (Poloxamer 188 and Soyalecithin) were used to prepare the aqueous phase. Poloxamer 188 is a non-ionic surfactant, added to the lipid nanoformulations as a steric stabilizer, to promotes electrostatic stabilization because it decreases the electrostatic repulsion between the nanoparticles by creating a coat around the surface for keeping the stability of lipid nanoparticles [29,41]. 
Table 3. Composition of irbesartan and irbesartan-HP $\beta C D$ complexed solid lipid nanoparticle formulations.

\begin{tabular}{|c|c|c|c|c|}
\hline Composition & IR-SLN1 & $\begin{array}{c}\text { IR-HP- } \beta \text { CD- } \\
\text { SLN1 }\end{array}$ & $\begin{array}{l}\text { IR- } \\
\text { SLN2 }\end{array}$ & $\begin{array}{c}\text { IR-HP- } \beta \text { CD- } \\
\text { SLN2 }\end{array}$ \\
\hline Irbesartan (mg) & 10 & - & 10 & - \\
\hline Irbesartan + HP $\beta C D(\mathrm{mg})$ * & - & 52.6 & - & 52.6 \\
\hline Glyceryl monostearate (mg) & 200 & 200 & - & - \\
\hline Dyanasn 112 (mg) & - & - & 200 & 200 \\
\hline Soyalecithin & 200 & 200 & 200 & 200 \\
\hline Poloxamer 188 (mg) & 150 & 150 & 150 & 150 \\
\hline Double distilled water up to (mL) & 10 & 10 & 10 & 10 \\
\hline
\end{tabular}

\subsection{PS, PDI, and ZP of IR-SLNs and IR-CD-SLNs}

Uptake and distribution of lipid-based nanoparticles by the lymphatic system depend on many factors such as molecular weight, type of lipid, PS, surface charge, surfactant concentration, and hydrophobicity [42]. Avoiding first-pass metabolism in the liver and GIT is the major advantage in drug delivery through uptake by the lymphatic system. The small PS of these formulations (20-500 nm) enables efficient uptake of drug molecules into the intestine, particularly via the lymphatic route [42,43]. PS, PDI, and ZP are depicted in Table 4. A homogeneous system with PS ranging from $240.2 \pm 6.7$ to $339.9 \pm 8.3 \mathrm{~nm}$, with a surface charge from $-20.5 \pm 4.1$ to $-30.5 \pm 4.1 \mathrm{mV}$ and PDI from $0.19 \pm 0.05$ to $0.29 \pm 0.08$ were obtained with $3.5 \% w / v$ concentration of surfactant. The prepared batches of SLNs, containing GMS showed a significant increase in PS compared to SLNs that contain Dynasan 112 as the solid lipid $(p<0.05)$. However, the prepared batches of SLNs, containing Dynasan 112 showed a significant increase in ZP compared to SLNs that contain GMS ( $p<0.05)$. Dynasan 112-based SLN dispersions showed a significantly lower PS than GMS-based SLN dispersions which could be due to the short hydrocarbon chain in the chemical structure of Dynasan 112 (Dodecanoic acid-based backbone) compared to the hydrocarbon chain in GMS (stearic acid-based backbone). However, GMS-based SLN dispersions showed a significantly lower ZP than Dynasan 112-based SLN dispersions which could be due to the fewer number of negatively charged carboxylic groups in the chemical structure of GMS (1 COO-) compared to the number of carboxylic groups in the chemical structure of Dynasan 112 (3 COO-). Nanoparticle formulations with PDI value $\leq 0.1$ is considered as highly monodisperse, while PDI value $>0.4$ is considered highly polydisperse and value in range of $0.1-0.4$ is considered to have a moderately disperse distribution [44].

Table 4. Physicochemical characteristics of IR-SLNs and IR-HP- $\beta C D-S L N s$ (mean $\pm S D, n=3$ ).

\begin{tabular}{cccccc}
\hline Formulation & Size $(\mathbf{n m})$ & PDI & ZP (mV) & Assay (\%) & EE (\%) \\
\hline IR-SLN1 & $300.7 \pm 4.8$ & $0.29 \pm 0.08$ & $-20.5 \pm 4.1$ & $99.2 \pm 1.4$ & $89.1 \pm 2.8$ \\
IR-HP- $\beta$ CD-SLN1 & $339.9 \pm 8.3$ & $0.28 \pm 0.02$ & $-22.6 \pm 3.4$ & $98.4 \pm 1.8$ & $86.9 \pm 1.8$ \\
IR-SLN2 & $240.2 \pm 6.7$ & $0.19 \pm 0.05$ & $-29.4 \pm 4.8$ & $98.7 \pm 1.5$ & $90.6 \pm 4.3$ \\
IR-HP- $\beta C D-S L N 2$ & $257.6 \pm 5.1$ & $0.21 \pm 0.03$ & $-30.5 \pm 4.1$ & $99.8 \pm 2.5$ & $93.7 \pm 2.5$ \\
\hline
\end{tabular}

\subsection{Assay and EE of IR-SLNs and IR-CD-SLNs}

EE and drug content in SLNs formulations were estimated by an HPLC and depicted in Table 4. EE ranged from $86.9 \pm 1.8$ to $93.7 \pm 2.5 \%$. Formulations containing Dynasan-112 showed slightly high values $(90.6 \pm 4.3 \%$ and $93.7 \pm 2.5 \%$ for IR-SLN2 and IR-HP- $\beta C D-$ SLN2) when compared to that of GMS $(89.1 \pm 2.8 \%$ and $86.9 \pm 1.8 \%$ for IR-SLN1and IR-HP- $\beta C D-S L N 1)$, which is statistically significant $(p<0.05)$ when IR-HP- $\beta C D-S L N 1$ is 
compared to IR-HP- $\beta$ CD-SLN2. SLN formulations prepared with Dynasan-112 as the lipid matrix resulted in higher drug entrapment than GMS. Dynasan-112 has a C12 triglyceride chain that could produce less ordered lipid crystals than GMS which is composed only of a monoester of stearic acid. This observation came in accordance with earlier reported studies [45]. The imperfection of the lipid structure could offer more void space to accommodate more drug molecules that is beneficial to increase drug loading capacity [45,46]. EE is also dependent on the amount of lipid, drug solubility in the lipid melt, and the concentration of surfactant [45]. Since the loaded drug molecules are located between the fatty acid chains of the lipid, between the lipid layers, and also in crystal imperfections, a highly ordered crystal lattice does not offer accommodation large amounts of drug molecules and consequently lead to drug expulsion during storage $[11,45]$. The drug content in the SLN dispersions ranged from $98.4 \pm 1.8$ to $99.8 \pm 2.5 \%$.

\subsection{In Vitro Release Studies of IR-SLNs and IR-CD-SLNs}

Based on the earlier reported solubility studies of IR in different dissolution media [47], Phosphate buffer ( $\mathrm{pH} 7.4$ ) with $40 \%$ ethanol was used as the receiver medium for in vitro release studies for $48 \mathrm{~h}$ by the dialysis method. The results are shown in Figure 3. During the in vitro release studies, a sustained release behavior of IR was observed. SLNs formulations containing Dynasan 112, and GMS showed drug release ranging from $65.9 \pm 0.2$ to $100.0 \pm 1.5 \%$ (IR-SLN2 and IR-HP- $\beta C D-S L N 2)$ and $55.5 \pm 1.1$ to $85.4 \pm 1.6 \%$ (IR-SLN1 and IR-HP- $\beta$ CD-SLN1). The IR suspension showed a quite fast release rate in the first $4 \mathrm{~h}$ because the fraction of free IR in solution was immediately ready to diffuse but rapidly reached a pseudo plateau phase during the next $44 \mathrm{~h}$, giving rise to a maximum of $45.2 \pm 1.0 \%$ drug released, whereas the IR-SLNs exhibited relatively high drug release $55.5 \pm 1.1 \%$ and $65.9 \pm 0.2 \%$ for IR-SLN1and IR-SLN2, respectively. IR is a lipophilic drug that belongs to the BCS class-II, and this could be a reason for the sustained release behavior from the lipid matrix of SLNs formulations. However, IR-CDSLNs exhibited high drug release $85.4 \pm 1.6 \%$ and $100.0 \pm 1.5 \%$ for IR-HP- $\beta C D-S L N 1$ and IR-HP- $\beta C D-S L N 2$. Loading of IR in combination with HP- $\beta C D$, both as Dynasan 112 or GMS formulations, improved the IR release rate from both SLNs formulations, compared to the IR suspension and the corresponding SLNSs containing IR alone. The enhancement of IR release rate exhibited by the two formulations containing IR/HP- $\beta C D$ inclusion complex could be due to the wetting and solubilizing effect of HP- $\beta C D$ towards IR [48]. Moreover, the increase in drug release rate was more evident in the case of SLNs, containing Dynasan 112, giving rise to a high \% drug release $(100.02 \pm 1.50 \%)$, where this observation could be due to the formation of the supercooled melts with an amorphous nature at room temperature. Based on literature review, it was observed that Dynasan-based nanoparticles could either exist into the solid crystalline state or the supercooled liquid state at room temperature. Supercooled melt behaves like O/W emulsions (liquid state), indicating that the mobility of drug molecules from supercooled melts is expected to occur easily [49]. Formulation containing Dynasan-112 (IR-SLN2 and IR-HP- $\beta$ CD-SLN2) showed a small PS (240.2 \pm 6.7 and $257.6 \pm 5.1 \mathrm{~nm})$, better PDI $(0.19 \pm 0.05$ and $0.21 \pm 0.03)$, a good value for $\mathrm{ZP}(-29.4 \pm 4.8$ and $-30.5 \pm 4.1 \mathrm{mV})$, high \% $\mathrm{EE}(90.6 \pm 4.3$ and $93.7 \pm 2.5)$, and release of $65.9 \pm 0.2$ and $100.0 \pm 1.5 \%$, respectively in a period of $48 \mathrm{~h}$ when compared to other formulations. Therefore, these two formulations were selected as the optimized formulations and used for further studies. 


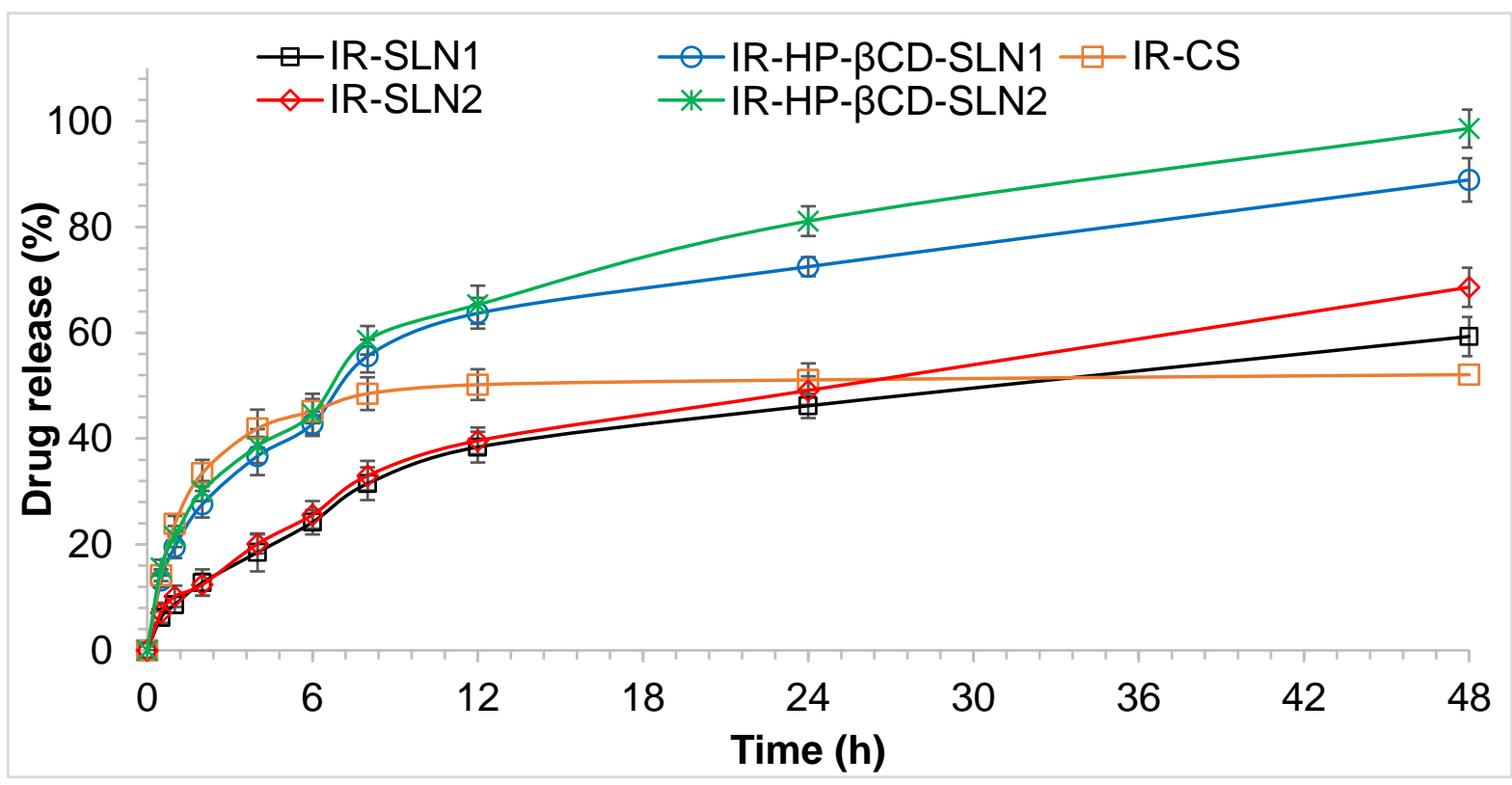

Figure 3. The in vitro release profile of irbesartan from IR-CS, IR-SLN, and IR-CD-SLN (mean \pm SD, $n=4)$.

\subsection{Stability Studies of the Optimized SLNs Formulation}

Stability studies were conducted for finally optimized formulation (IR- $\beta C D$, IR-HP$\beta C D$, IR-SLN2, and HP- $\beta C D$-SLN2) at RT for two months. The two inclusion complexes showed no significant $(p>0.05)$ changes in drug content and inclusion efficiency. Some changes were observed in ZP, PDI, assay, \% EE, and PS values, but statistically insignificant as shown in Table 5.

Table 5. Effect of storage at room temperature on physicochemical characteristics of the optimized SLN formulations (mean $\pm \mathrm{SD}, n=3$ ).

\begin{tabular}{|c|c|c|c|c|c|c|c|c|c|c|}
\hline \multirow[b]{2}{*}{ Day } & \multicolumn{5}{|c|}{ IR-HP- $\beta$ CD-SLN2 } & \multicolumn{5}{|c|}{ IR-SLN2 } \\
\hline & $\begin{array}{l}\text { Size } \\
(\mathrm{nm})\end{array}$ & PDI & $\mathrm{ZP}(\mathrm{mV})$ & Assay (\%) & EE (\%) & $\begin{array}{l}\text { Size } \\
(\mathrm{nm})\end{array}$ & PDI & $\underset{(\mathrm{mV})}{\mathrm{ZP}}$ & Assay (\%) & $\begin{array}{l}\text { EE } \\
(\%)\end{array}$ \\
\hline 1 & $251.4 \pm 7.6$ & $0.21 \pm 0.03$ & $-30.5 \pm 4.1$ & $99.8 \pm 2.5$ & $92.4 \pm 1.6$ & $234.8 \pm 7.2$ & $0.20 \pm 0.02$ & $-29.1 \pm 3.1$ & $97.9 \pm 1.9$ & $91.1 \pm 2.5$ \\
\hline 30 & $261.5 \pm 3.9$ & $0.23 \pm 0.05$ & $-28.6 \pm 2.0$ & $97.6 \pm 1.7$ & $90.7 \pm 2.2$ & $244.3 \pm 5.9$ & $0.21 \pm 0.04$ & $-28.2 \pm 2.7$ & $98.3 \pm 2.1$ & $90.2 \pm 1.9$ \\
\hline 60 & $276.6 \pm 5.8$ & $0.23 \pm 0.06$ & $-27.9 \pm 2.9$ & $96.9 \pm 2.6$ & $90.1 \pm 1.9$ & $256.3 \pm 8.6$ & $0.22 \pm 0.05$ & $-29.6 \pm 4.4$ & $96.8 \pm 1.5$ & $88.6 \pm 2.2$ \\
\hline
\end{tabular}

\subsection{Lyophilization}

The transformation from liquid form to solid form could offer possibilities for incorporating SLNs into pellets, capsules, and tablets [45]. Furthermore, freeze-drying of SLN dispersions yields dry products that can be conveniently stored and reconstituted before use by adding an aqueous medium. Lyophilization could increase the stability of SLN dispersions for a longer period because the aqueous SLNs formulations are liable to physicochemical stability problems [45]. High sublimation velocities and high specific surface areas were reported for the diluted dispersions of SLNs [45]. Therefore, trehalose was required as a cryoprotectant to ensure the ease of redispersion of the freeze-dried powder without any aggregation [45]. The cryoprotectant forms a kind of 'pseudo hydration shell' by the interaction with the hydrophilic head groups of the surfactant molecules [45]. Freeze-dried SLNs powder was diluted (1 to 50) with filtered double distilled water. The behavior during freeze-drying of SLNs dispersion was studied with respect to PS, PDI, and $\mathrm{ZP}$, and the data is shown in Table 6. A significant increase in PS and PDI was observed $(p<0.05)$. However, an insignificant change in ZP was observed $(p>0.05)$. The freezedrying process could modify the PS and the shape of the SLNs [50]. The increase in PS and PDI is due to nanoparticles aggregation due to lyophilization. The observation was consistent with many earlier reported studies [45,51,52]. 
Table 6. Pre- and post-lyophilization effect on physicochemical characteristics of the optimized IR-SLN and IR-CD-SLN formulation (mean $\pm \mathrm{SD}, n=3$ ).

\begin{tabular}{|c|c|c|c|c|c|c|c|c|c|c|}
\hline \multirow[b]{2}{*}{ Formulation } & \multicolumn{5}{|c|}{ Pre-lyophilization } & \multicolumn{5}{|c|}{ Post-lyophilization } \\
\hline & $\begin{array}{l}\text { Size } \\
(\mathrm{nm})\end{array}$ & PDI & $\begin{array}{c}\mathrm{ZP} \\
(\mathrm{mV})\end{array}$ & Assay (\%) & $\begin{array}{l}\mathrm{EE} \\
(\%)\end{array}$ & $\begin{array}{l}\text { Size } \\
(\mathrm{nm})\end{array}$ & PDI & $\mathrm{ZP}(\mathrm{mV})$ & $\begin{array}{l}\text { Assay } \\
(\%)\end{array}$ & $\begin{array}{l}\mathrm{EE} \\
(\%)\end{array}$ \\
\hline $\begin{array}{l}\text { IR-HP- } \beta C D- \\
\text { SLN2 }\end{array}$ & $270.3 \pm 8.6$ & $0.24 \pm 0.05$ & $-28.9 \pm 2.7$ & $98.1 \pm 1.6$ & $91.6 \pm 1.9$ & $465.7 \pm 10.5$ & $0.43 \pm 0.06$ & $-26.5 \pm 1.3$ & $97.6 \pm 2.1$ & $92.3 \pm 1.6$ \\
\hline IR-SLN2 & $251.3 \pm 4.9$ & $0.21 \pm 0.02$ & $-31.9 \pm 1.8$ & $99.3 \pm 2.0$ & $89.6 \pm 1.7$ & $410.6 \pm 11.9$ & $0.23 \pm 0.06$ & $-29.3 \pm 2.3$ & $97.6 \pm 2.7$ & $88.9 \pm 2.1$ \\
\hline
\end{tabular}

\subsection{DSC}

Thermal analysis techniques, mainly DSC, are broadly used in the pharmaceutical formulation field, starting from the quality control of raw materials to stability, and preformulation studies for the development of new formulations. DSC thermograms were used to determine the compatibility status of the drug, $\mathrm{CDs}$, and lipids used in the preparation of SLN and CD-SLN formulations. Figure 4 shows the DSC thermograms of pure IR, pure HP- $\beta C D$, pure Dynasan 112, PM of drug and lipid (1:1), freeze-dried IR/HP- $\beta C D$ inclusion complex (1:1), lyophilized IR-SLN2, and lyophilized IR-HP- $\beta$ CD-SLN2 formulations. The DSC thermogram of pure IR and Dynasan- 112 showed endothermic peaks at $185^{\circ} \mathrm{C}$ and $48.56^{\circ} \mathrm{C}$, respectively $[45,53]$. The thermal curve of HP- $\beta C D$ showed a broad endothermic peak at $90.11^{\circ} \mathrm{C}$ corresponding to the dehydration and decomposition of HP- $\beta C D$ [54]. The disappearance of the endothermic peak that corresponds to the melting point of pure IR was observed upon performing a similar DSC analysis of the freeze-dried inclusion complex. This observation confirms the formation of the inclusion complex of IR with HP- $\beta C D$. PM (1:1) of IR with Dynasan 112 showed IR peak at $200^{\circ} \mathrm{C}$; however, with less enthalpy and the endothermic peak of the lipid was slightly shifted to a lower temperature $\left(47.82^{\circ} \mathrm{C}\right)$. In general, the drug endotherm was well preserved. The absence of endothermic peak of IR in lyophilized IR-SLN2 and IR- $\beta$ CD-SLN2 formulations indicated the conversion from crystalline to the amorphous form of IR molecules. The DSC curves did not show the characteristic IR peaks in SLN formulations due to the dispersion of the IR within the lipid matrix; the observed peaks are due to the solid lipid. The phase transition temperatures of colloidal dispersions were always significantly lower than those of anhydrous lipid mixtures [45]. In the case of colloidal SLN and CD-SLN dispersion systems, about a $5-10{ }^{\circ} \mathrm{C}$ decrease in the melting point of the lipid was observed. The phase transition temperature and enthalpy of the SLN formulation were much lower than those of the corresponding anhydrous physical mixture, as previously reported $[45,55,56]$.

\subsection{PXRD}

$X R D$ is a useful instrumental tool in the analysis, examination, monitoring of the crystal morphology of different drugs and excipients, used in drug formulation. Any changes that occurred in the crystalline state of drugs and excipients in the final product or formulation can be detected. XRD patterns of IR, HP- $\beta C D$, IR-HP- $\beta C D$ inclusion complex (1:1 molar ratio), Dynasan 112, IR-Dynasan 112 PM, freeze-dried IR-SLN2, and IR-HP$\beta C D-S L N 2$ are shown in Figure 5. The XRD pattern of pure IR exhibits intense peaks at $2 \theta$ angles of $9.35^{\circ}, 12.41^{\circ}, 17.92^{\circ}$, and $23.05^{\circ}$ which reveals the crystallinity characteristic of the drug [57]. The characteristic peaks of IR existed in the IR/Dynasan 112 PM. HP$\beta C D$ demonstrated only one broad peak centered at $20.5^{\circ}$ which is consistent with its amorphous state. The XRD patterns of the freeze-dried IR/HP- $\beta C D$ inclusion complex exhibited typical halo patterns for its amorphous structure, showing IR might be fully included in the cavity of HP- $\beta C D$ [58]. The disappearance of IR peaks in the freeze-dried CD-SLN formulation indicated that IR was not existed in the crystalline state due to lyophilization [45]. Furthermore, the lyophilized formulation showed a decrease in the intensity of the characteristic lipid peaks and demonstrated the decreased crystallinity of the lipid. The XRD pattern did not also show the characteristic IR peaks in the lyophilized 
SLNs formulation due to the dispersion of the IR within the lipid matrix. X-ray diffraction data came in accordance with the DSC studies [59].

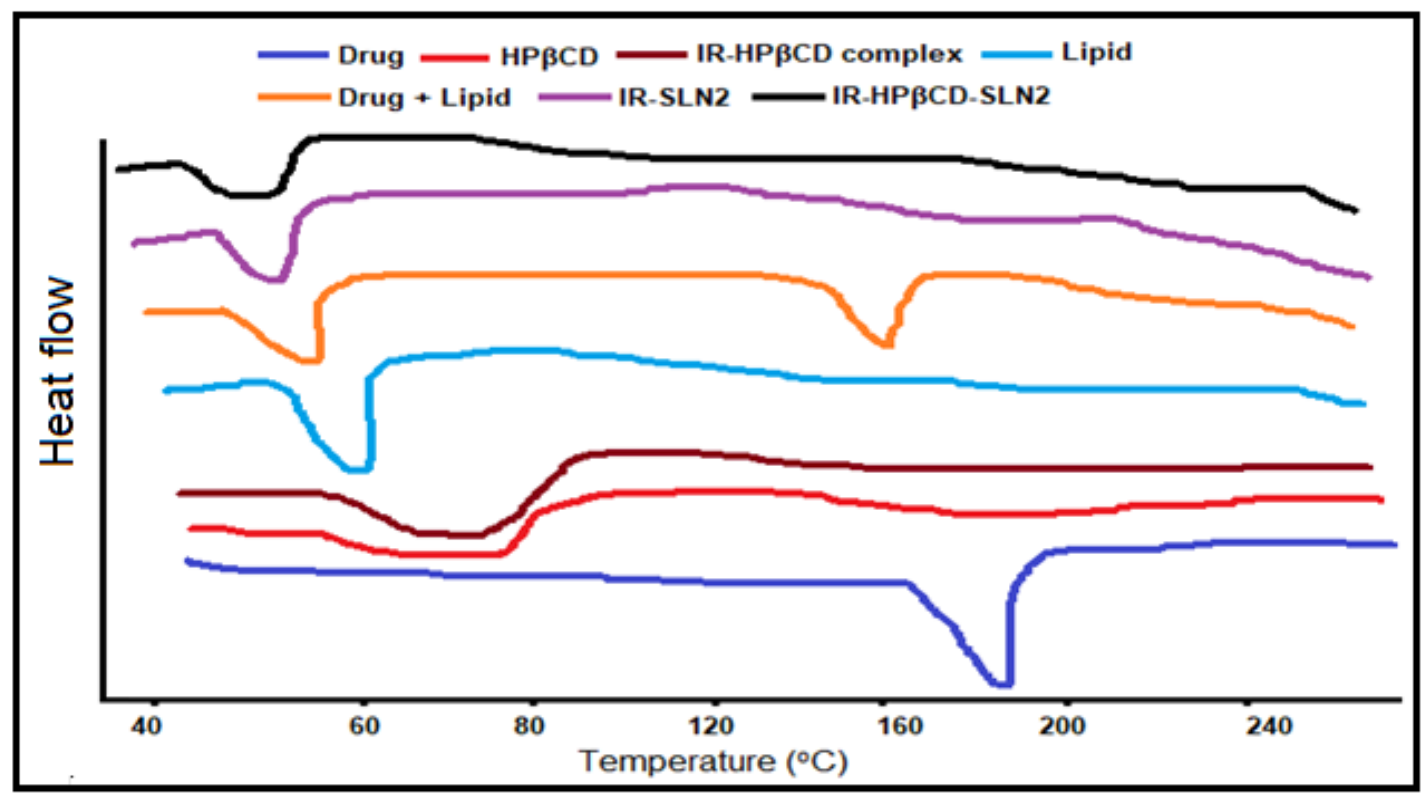

Figure 4. DSC curves of IR, HP- $\beta C D$, freeze-dried IR/HP- $\beta C D$ inclusion complex (1:1 molar ratio), Dynasan 112 , PM of IR, and Dynasan 112, freeze-dried IR-SLN2, and freeze-dried IR-HP- $\beta$ CD-SLN2 formulations.

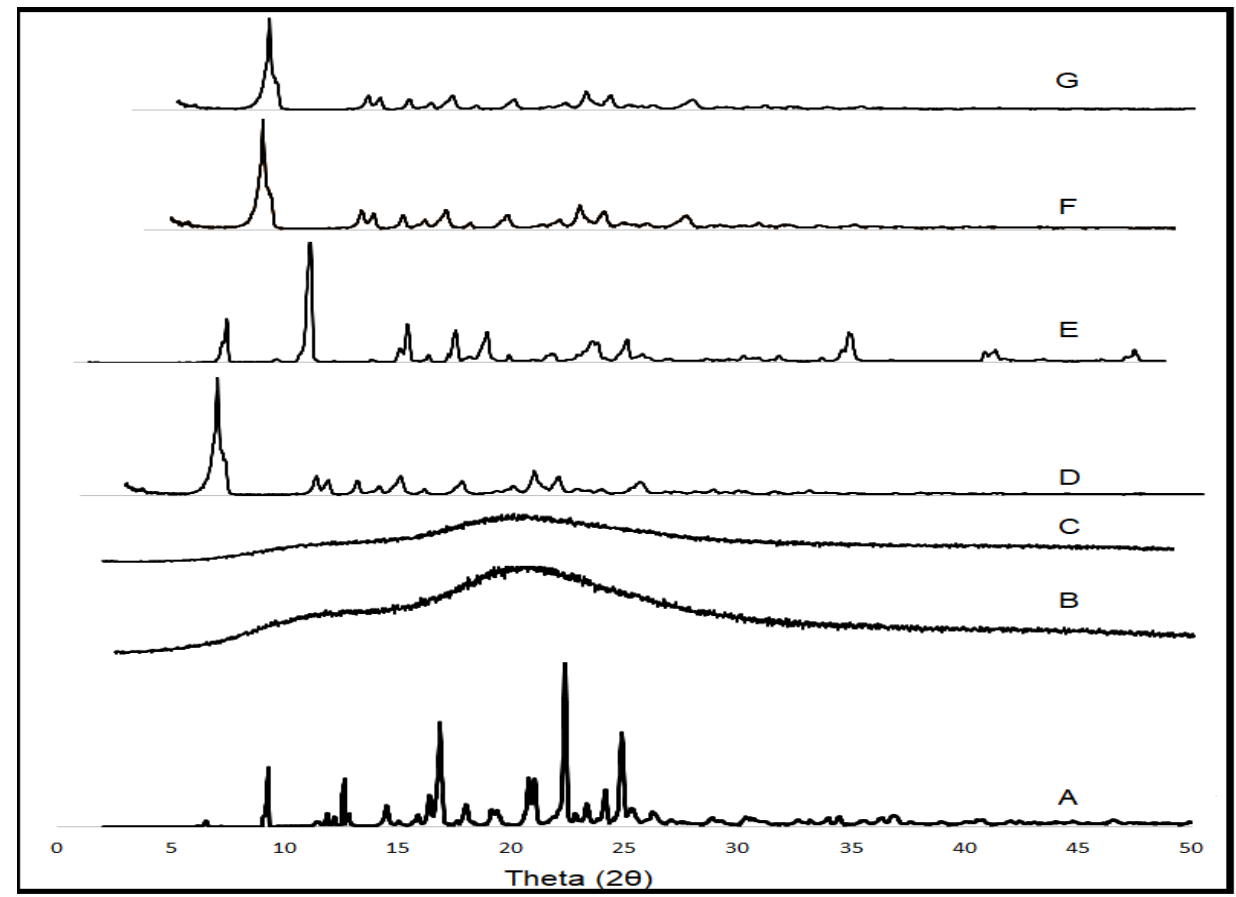

Figure 5. X-ray diffraction patterns of (A) IR, (B) HP- $\beta C D,(C)$ IR-HP- $\beta C D$ inclusion complex (1:1 molar ratio), (D) Dynasan 112, (E) IR + Dynasan 112 physical mixture, (F) lyophilized IR-SLN2 formulation, and $(\mathrm{G})$ lyophilized IR-HP- $\beta C D-S L N 2$ formulation.

\section{Conclusions}

This study reports the successful preparation and optimization of a formulation based on the loading of IR-CD inclusion complex into SLNs for developing an oral liquid formulation of IR with enhanced solubility, sustained release profile, and could improve therapeutic efficacy. Of the tested CDs, HP- $\beta C D$ was chosen based on its better performance in the 
in vitro release studies. The optimized IR-CD-SLNs were found to have small PS, narrow $\mathrm{PDI}$, and a high entrapment efficiency with minimum stability of 2 months at room temperature. The two SLN formulations containing IR/HP- $\beta C D$ inclusion complex exhibited enhancement of the drug release rate and sustained the drug release also. The optimized nanodispersions were lyophilized to improve the stability. However, morphology studies by scanning and transmission electron microscopy, long term stability studies at refrigerated and room temperature storage conditions, and ex vivo and in vivo pharmacokinetic studies are additional studies that are required for the formulation to be developed into an oral dosage form for the treatment of hypertension and heart failure. Thus, the present study suggests the potential development of nanoparticulate formulations for oral delivery of IR for the treatment of hypertension and heart failure.

Author Contributions: Conceptualization, methodology, N.D.; software, A.A.A.Y., validation, N.D., S.E. formal analysis, N.D., S.E., G.P.; investigation, N.D., S.E.; resources, G.P.; data curation, N.D., S.E., A.A.A.Y.; writing-original draft preparation, N.D., A.A.A.Y.; writing-review and editing, N.D., S.E., G.P.; visualization, N.D., G.P.; supervision, N.D.; project administration, N.D., G.P. funding acquisition, N.D., G.P. All authors have read and agreed to the published version of the manuscript.

Funding: This research received no external funding.

Data Availability Statement: Data provided upon request, if needed.

Conflicts of Interest: The authors declare no conflict of interest.

Sample Availability: Not applicable.

\section{References}

1. Alqahtani, M.S.; Kazi, M.; Alsenaidy, M.A.; Ahmad, M.Z. Advances in Oral Drug Delivery. Front. Pharmacol. 2021, $12,62$. [CrossRef] [PubMed]

2. Prasad, V.; De Jesus-Morales, K.; Mailankody, S. The High Price of Anticancer Drugs: Origins, Implications, Barriers, Solutions. Nat. Rev. Clin. Oncol. 2017, 14, 381-390. [CrossRef]

3. Dudhipala, N. A Comprehensive Review on Solid Lipid Nanoparticles as Delivery Vehicle for Enhanced Pharmacokinetic and Pharmacodynamic Activity of Poorly Soluble Drugs. Int. J. Pharm. Sci. Nanotechnol. 2019, 12, 20. [CrossRef]

4. Bummer, P.M. Physical Chemical Considerations of Lipid-Based Oral Drug Delivery-Solid Lipid Nanoparticles. CRT 2004, 21, 1-20. [CrossRef]

5. Aungst, B.J. Absorption Enhancers: Applications and Advances. AAPS J. 2012, 14, 10-18. [CrossRef]

6. Gaucher, G.; Dufresne, M.-H.; Sant, V.P.; Kang, N.; Maysinger, D.; Leroux, J.-C. Block Copolymer Micelles: Preparation, Characterization and Application in Drug Delivery. J. Control. Release 2005, 109, 169-188. [CrossRef]

7. Blagden, N.; de Matas, M.; Gavan, P.T.; York, P. Crystal Engineering of Active Pharmaceutical Ingredients to Improve Solubility and Dissolution Rates. Adv. Drug Deliv. Rev. 2007, 59, 617-630. [CrossRef] [PubMed]

8. Lu, J.; Shah, S.; Jo, S.; Majumdar, S.; Gryczke, A.; Kolter, K.; Langley, N.; Repka, M.A. Investigation of Phase Diagrams and Physical Stability of Drug-Polymer Solid Dispersions. Pharm. Dev. Technol. 2015, 20, 105-117. [CrossRef] [PubMed]

9. Loftsson, T.; Brewster, M.E. Pharmaceutical Applications of Cyclodextrins. 1. Drug Solubilization and Stabilization. J. Pharm. Sci. 1996, 85, 1017-1025. [CrossRef]

10. Shirodkar, R.K.; Kumar, L.; Mutalik, S.; Lewis, S. Solid Lipid Nanoparticles and Nanostructured Lipid Carriers: Emerging Lipid Based Drug Delivery Systems. Pharm. Chem. J. 2019, 53, 440-453. [CrossRef]

11. Dudhipala, N. Influence of solid lipid nanoparticles on pharmaco-dynamic activity of poorly oral bioavailable drugs. Int. J. Pharm. Sci. Nanotechnol. 2020, 13, 4979-4983. [CrossRef]

12. MuÈller, R.H.; MaĖder, K.; Gohla, S. Solid Lipid Nanoparticles (SLN) for Controlled Drug Delivery \pm a Review of the State of the Art. Eur. J. Pharm. Biopharm. 2000, 17, 161-177. [CrossRef]

13. Hines, J.; Fluharty, S.J.; Sakai, R.R. The Angiotensin AT1 Receptor Antagonist Irbesartan Has Near-Peptide Affinity and Potently Blocks Receptor Signaling. Eur. J. Pharmacol. 1999, 384, 81-89. [CrossRef]

14. Puri, V.; Nagpal, M.; Sharma, A.; Thakur, G.S.; Singh, M.; Aggarwal, G. Development of Binary Dispersions and Nanocomposites of Irbesartan with Enhanced Antihypertensive Activity. Bioimpacts 2020, 10, 269-278. [CrossRef]

15. Rajeswari, K.R.; Brungi, V.; Bennuru, S.; Cheeli, S.; Vankadari, R.G. Studies on the Development of Orally Disintegrating Tablets of Irbesartan. Asian J. Pharm. Res. 2020, 10, 01-07. [CrossRef]

16. Vyas, A.; Saraf, S.; Saraf, S. Cyclodextrin Based Novel Drug Delivery Systems. J. Incl. Phenom. Macrocycl. Chem. 2008, 20, 23-42. [CrossRef] 
17. Leonis, G.; Christodoulou, E.; Ntountaniotis, D.; Chatziathanasiadou, M.; Mavromoustakos, T.; Naziris, N.; Chountoulesi, M.; Demetzos, C.; Valsami, G.; Damalas, D.; et al. Antihypertensive Activity and Molecular Interactions of Irbesartan in Complex with 2-hydroxypropyl- $\beta$-cyclodextrin. Chem. Biol. Drug Des. 2020, 96, 668-683. [CrossRef] [PubMed]

18. Liossi, A.S.; Ntountaniotis, D.; Kellici, T.F.; Chatziathanasiadou, M.V.; Megariotis, G.; Mania, M.; Becker-Baldus, J.; Kriechbaum, M.; Krajnc, A.; Christodoulou, E.; et al. Exploring the Interactions of Irbesartan and Irbesartan-2-Hydroxypropyl- $\beta$-Cyclodextrin Complex with Model Membranes. Biochim. Biophys. Acta Biomembr. 2017, 1859, 1089-1098. [CrossRef]

19. Soma, D.; Attari, Z.; Reddy, M.S.; Damodaram, A.; Koteshwara, K.B.G. Solid Lipid Nanoparticles of Irbesartan: Preparation, Characterization, Optimization and Pharmacokinetic Studies. Braz. J. Pharm. Sci. 2017, 53, 1-10. [CrossRef]

20. Alanazi, A.M.; Abdelhameed, A.S.; Khalil, N.Y.; Khan, A.A.; Darwish, I.A. HPLC Method with Monolithic Column for Simultaneous Determination of Irbesartan and Hydrochlorothiazide in Tablets. Acta Pharm. 2014, 64, 187-198. [CrossRef]

21. Nicolescu, C.; Aram, C.; Nedelcu, A.; Monciu, C.-M. Phase solubility studies of the inclusion complexes of repaglinide with $\beta$-cyclodextrin and $\beta$-cyclodextrin derivatives. Farmacia 2010, 58, 620-628.

22. Hirlekar, R.; Kadam, V. Preformulation Study of the Inclusion Complex Irbesartan- $\beta$-Cyclodextrin. AAPS PharmSciTech 2009, 10, 276-281. [CrossRef]

23. Dudhipala, N.; Veerabrahma, K. Pharmacokinetic and Pharmacodynamic Studies of Nisoldipine-Loaded Solid Lipid Nanoparticles Developed by Central Composite Design. Drug Dev. Ind. Pharm. 2015, 41, 1968-1977. [CrossRef]

24. Gondrala, U.K.; Dudhipala, N.; Kishan, V. Preparation, Characterization and In Vivo Evaluation of Felodipine Solid-Lipid Nanoparticles for Improved Oral Bioavailability. Int. J. Pharm. Sci. Nanotechnol. 2015, 8, 9.

25. Dudhipala, N.; Puchchakayala, G. Capecitabine Lipid Nanoparticles for Anti-Colon Cancer Activity in 1,2-DimethylhydrazineInduced Colon Cancer: Preparation, Cytotoxic, Pharmacokinetic, and Pathological Evaluation. Drug Dev. Ind. Pharm. 2018, 44, 1572-1582. [CrossRef] [PubMed]

26. Thirupathi, G.; Swetha, E.; Narendar, D. Role of Isradipine Loaded Solid Lipid Nanoparticles on the Pharmacodynamic Effect in Rats. Drug Res. 2017, 67, 163-169. [CrossRef] [PubMed]

27. Nagaraj, K.; Narendar, D.; Kishan, V. Development of Olmesartan Medoxomil Optimized Nanosuspension Using the Box-Behnken Design to Improve Oral Bioavailability. Drug Dev. Ind. Pharm. 2017, 43, 1186-1196. [CrossRef]

28. Dudhipala, N.; Janga, K.Y.; Gorre, T. Comparative Study of Nisoldipine-Loaded Nanostructured Lipid Carriers and Solid Lipid Nanoparticles for Oral Delivery: Preparation, Characterization, Permeation and Pharmacokinetic Evaluation. Artif. Cells Nanomed. Biotechnol. 2018, 46, 616-625. [CrossRef]

29. Youssef, A.; Dudhipala, N.; Majumdar, S. Ciprofloxacin Loaded Nanostructured Lipid Carriers Incorporated into In-Situ Gels to Improve Management of Bacterial Endophthalmitis. Pharmaceutics 2020, 12, 572. [CrossRef]

30. Liu, L.; Guo, Q.-X. The Driving Forces in the Inclusion Complexation of Cyclodextrins. J. Incl. Phenom. Macrocycl. Chem. 2002, 42, 1-14. [CrossRef]

31. Narendar, D.; Ettireddy, S. Influence of $\beta$-Cyclodextrin and Hydroxypropyl- $\beta$-Cyclodextrin on Enhancement of Solubility and Dissolution of Isradipine. Int. J. Pharm. Sci. Nanotechnol. 2017, 10, 3752-3757.

32. Challa, R.; Ahuja, A.; Ali, J.; Khar, R.K. Cyclodextrins in Drug Delivery: An Updated Review. AAPS PharmSciTech 2005, 6, E329-E357. [CrossRef]

33. Higuchi, T. A Phase Solubility Technique. Adv. Anal. Chem. Instrum. 1965, 4, 117-211.

34. Loftsson, T.; Vogensen, S.B.; Brewster, M.E.; Konráðsdóttir, F. Effects of Cyclodextrins on Drug Delivery through Biological Membranes. J. Pharm. Sci. 2007, 96, 2532-2546. [CrossRef] [PubMed]

35. Connors, K.A. Population Characteristics of Cyclodextrin Complex Stabilities in Aqueous Solution. J. Pharm. Sci. 1995, 84, 843-848. [CrossRef] [PubMed]

36. Torrado, S.; Torrado, S.; Torrado, J.J.; Cadórniga, R. Preparation, Dissolution and Characterization of Albendazole Solid Dispersions. Int. J. Pharm. 1996, 140, 247-250. [CrossRef]

37. Podczeck, F.; Jones, B.E. The In Vitro Dissolution of Theophylline from Different Types of Hard Shell Capsules. Drug Dev. Ind. Pharm. 2002, 28, 1163-1169. [CrossRef]

38. Loftsson, T.; Másson, M.; Brewster, M.E. Self-Association of Cyclodextrins and Cyclodextrin Complexes. J. Pharm. Sci. 2004, 93, 1091-1099. [CrossRef]

39. Brewster, M.E.; Loftsson, T. Cyclodextrins as Pharmaceutical Solubilizers. Adv. Drug Deliv. Rev. 2007, 59, 645-666. [CrossRef]

40. Messner, M.; Kurkov, S.V.; Jansook, P.; Loftsson, T. Self-Assembled Cyclodextrin Aggregates and Nanoparticles. Int. J. Pharm. 2010, 387, 199-208. [CrossRef]

41. Youssef, A.A.A.; Cai, C.; Dudhipala, N.; Majumdar, S. Design of Topical Ocular Ciprofloxacin Nanoemulsion for the Management of Bacterial Keratitis. Pharmaceuticals 2021, 14, 210. [CrossRef]

42. Khan, A.A.; Mudassir, J.; Mohtar, N.; Darwis, Y. Advanced Drug Delivery to the Lymphatic System: Lipid-Based Nanoformulations. Int J. Nanomed. 2013, 8, 2733-2744. [CrossRef]

43. Yuan, H.; Chen, J.; Du, Y.-Z.; Hu, F.-Q.; Zeng, S.; Zhao, H.-L. Studies on Oral Absorption of Stearic Acid SLN by a Novel Fluorometric Method. Colloids Surf. B Biointerfaces 2007, 58, 157-164. [CrossRef] [PubMed]

44. Bhattacharjee, S. DLS and Zeta Potential-What They Are and What They Are Not? J. Control. Release 2016, 235, 337-351. [CrossRef] [PubMed] 
45. Dudhipala, N.; Veerabrahma, K. Improved Anti-Hyperlipidemic Activity of Rosuvastatin Calcium via Lipid Nanoparticles: Pharmacokinetic and Pharmacodynamic Evaluation. Eur. J. Pharm. Biopharm. 2017, 110, 47-57. [CrossRef] [PubMed]

46. Hou, D.; Xie, C.; Huang, K.; Zhu, C. The Production and Characteristics of Solid Lipid Nanoparticles (SLNs). Biomaterials 2003, 24, 1781-1785. [CrossRef]

47. Haneef, J.; Chadha, R. Drug-Drug Multicomponent Solid Forms: Cocrystal, Coamorphous and Eutectic of Three Poorly Soluble Antihypertensive Drugs Using Mechanochemical Approach. AAPS PharmSciTech 2017, 18, 2279-2290. [CrossRef]

48. Cirri, M.; Maestrini, L.; Maestrelli, F.; Mennini, N.; Mura, P.; Ghelardini, C.; Di Cesare Mannelli, L. Design, Characterization and in Vivo Evaluation of Nanostructured Lipid Carriers (NLC) as a New Drug Delivery System for Hydrochlorothiazide Oral Administration in Pediatric Therapy. Drug Deliv. 2018, 25, 1910-1921. [CrossRef]

49. Westesen, K.; Bunjes, H.; Koch, M.H.J. Physicochemical Characterization of Lipid Nanoparticles and Evaluation of Their Drug Loading Capacity and Sustained Release Potential. J. Control. Release 1997, 48, 223-236. [CrossRef]

50. Dudhipala, N.R.; Ettireddy, S.R.; Puchakayala, G.R. Attenuation of lipid levels in triton induced hyperlipidemia rats through rosuvastatin calcium nanoparticles: Pharmacokinetic and pharmacodynamic studies. Chem. Phys. Lipids 2021, $237,105081$. [CrossRef]

51. Pikal, M.J.; Shah, S.; Roy, M.L.; Putman, R. The Secondary Drying Stage of Freeze Drying: Drying Kinetics as a Function of Temperature and Chamber Pressure. Int. J. Pharm. 1990, 60, 203-207. [CrossRef]

52. Dudhipala, N.; Ay, A.A. Amelioration of ketoconazole in lipid nanoparticles for enhanced antifungal activity and bioavailability through oral administration for management of fungal infections. Chem. Phys. Lipids 2020, 232, 104953. [CrossRef] [PubMed]

53. Zhang, Z.-L.; Le, Y.; Wang, J.-X.; Chen, J.-F. Preparation of Stable Micron-Sized Crystalline Irbesartan Particles for the Enhancement of Dissolution Rate. Drug Dev. Ind. Pharm. 2011, 37, 1357-1364. [CrossRef]

54. Su, J.; Chen, J.; Li, L.; Li, B.; Shi, L.; Zhang, H.; Ding, X. Preparation of Natural Borneol/2-Hydroxypropyl- $\beta$-Cyclodextrin Inclusion Complex and Its Effect on the Absorption of Tetramethylpyrazine Phosphate in Mouse. Chem. Pharm. Bull. 2012, 60, 736-742. [CrossRef] [PubMed]

55. Mobley, W.; Schreier, H. Phase Transition Temperature Reduction and Glass Formation in Dehydroprotected Lyophilized Liposomes. J. Control. Release 1994, 31, 73-87. [CrossRef]

56. Dudhipala, N.; Veerabrahma, K. Candesartan cilexetil loaded solid lipid nanoparticles for oral delivery: Characterization, pharmacokinetic and pharmacodynamic evaluation. Drug Deliv. 2016, 23, 395-404. [CrossRef] [PubMed]

57. Kamble, R.; Gaikwad, S.; Maske, A.; Patil, S. Fabrication of Elecrospun Nanofibres of BCS II Drug for Enhanced Dissolution and Permeation across Skin. J. Adv. Res. 2016, 7, 483-489. [CrossRef] [PubMed]

58. Mokhtar, M.S.; Suliman, F.O.; Elbashir, A.A. Experimental and Molecular Modeling Investigations of Inclusion Complexes of Imazapyr with 2-Hydroxypropyl $(\beta / \gamma)$ Cyclodextrin. J. Mol. Liq. 2018, 262, 504-513. [CrossRef]

59. Dudhipala, N.; Gorre, T. Neuroprotective effect of ropinirole lipid nanoparticles enriched hydrogel for parkinson's disease: In vitro, ex vivo, pharmacokinetic and pharmacodynamic evaluation. Pharmaceutics 2020, 12, 448. [CrossRef] [PubMed] 